Revista Digital Universitaria

Vol. 23, Núm. 1, enero-febrero 2022

\title{
EI SUAyED y su papel ante la desigualdad educativa
}

\author{
Mariana Soberanes González
}

\begin{abstract}
Resumen
A través del Sistema Universidad Abierta y Educación a Distancia (sUAYED), la Universidad Nacional Autónoma de México (UNAM) coadyuva a disminuir la brecha educativa en el nivel de educación superior al permitir mejorar las condiciones de vida de la población que de otra manera no puede tener acceso a estudiar una licenciatura. México es un país con amplias desigualdades sociales que ocasionan que muchas personas deserten de sus estudios para cubrir otras necesidades, principalmente económicas. Este artículo da a conocer el papel activo del SUAYED de la UNAM en la reducción de dichas desigualdades educativas y, en consecuencia, sociales. Asimismo, doy a conocer mi experiencia como estudiante de este sistema para que, a través de ella, algunos encuentren dentro de este sistema de estudio una posibilidad de cumplir sus metas universitarias.
\end{abstract}

Palabras clave: rezago educativo, acceso a la educación, educación continua, educación abierta, educación a distancia.

\section{The SUAyED AND ITS ROLE IN THE FACE OF EDUCATIONAL INEQUALITY. 50TH AN- NIVERSARY}

\begin{abstract}
Through the Open University and Distance Education System (SUAYED), the National Autonomous University of Mexico (UNAM) helps to reduce the educational gap in the level of higher education by allowing to improve the living conditions of the population that otherwise does not you can have access to study a bachelor's degree. Mexico is a country with wide social inequ alities that cause many people to drop out of their studies to meet other needs, mainly economic. This article reveals the active role of the SUAYED of the UNAM in reducing said educational and, consequently, social inequalities. Likewise, I present my experience as a student of this system so that, through it, some may find within this study system a possibility to meet their university goals.
\end{abstract}

Keywords: educational lagging, access to education, continuing education, open education, distance education 
"EI SUAyED y su papel ante la desigualdad educativa"

Mariana Soberanes González

Vol. 23, Núm. 1, enero-febrero 2022

Revista Digital Universitaria

Mariana Soberanes González

masoberanesg@gmail.com

mariana.soberanesg@yahoo.com.mx

orcid.org/0000-0002-0707-8957

Egresada de la carrera de Pedagogía de la Facultad de Filosofía y Letras de la UNAM dentro del Sistema Universidad Abierta y Educación a Distancia (SUAYED). Desde el año 2013 ha colaborado en programas sociales de la actual Secretaría de Educación, Ciencia, Tecnología e Innovación de la Ciudad de México, en los que ha brindado acompañamiento académico a jóvenes y adultos en los niveles de alfabetización, alfabetización digital, primaria, secundaria y bachillerato, así como atención a personas con discapacidad auditiva. Sus líneas de investigación se centran en las herramientas que permitan disminuir las brechas educativas de personas jóvenes y adultas con discapacidad auditiva. Asimismo, en el diseño de planes que contribuyan a reducir el índice de analfabetismo.

\section{Rezago educativo y matrícula de educación superior}

U

na persona se encuentra en situación de rezago educativo cuando no ha concluido los estudios que se supone que tendría que cursar de acuerdo a su rango de edad. Éste puede presentarse en la educación básica, media superior o superior.

En ese sentido, el Consejo Nacional de Evaluación de la Política de Desarrollo Social (CONEVAL) sostiene que este rezago está intrínsecamente relacionado con la pobreza. Es decir, entre mayor sea la pobreza, menor es el nivel educativo de la población. Y esta relación puede mantenerse de manera generacional, de tal manera que entre menor sea el nivel educativo de los padres, menor será el nivel educativo de los hijos. Sin embargo, es de suma importancia romper este tipo de paradigmas predeterministas que obstaculizan el desarrollo de la sociedad.

En relación a lo anterior y con base a las estadísticas del INEGI (2020), el CONEVAL realizó las estimaciones de la medición multidimensional de la pobreza, las cuales muestran que entre 2018 y 2020 el rezago educativo aumentó en 0.3 puntos porcentuales al pasar de 19.0\% a 19.2\%, respectivamente. (CONEVAL, 2020).

Siguiendo el hilo del rezago educativo, y de acuerdo con el último censo de población y vivienda, en México hay 126,014,024 de habitantes, de los cuales $66 \%$ se encuentra en el rango de edad de 20 años y más, lo que se supone que están en edad de estudiar o haber concluido una licenciatura. Sin embargo, de esta cifra tan sólo $21.6 \%$ de la población ha logrado llegar a la educación superior, lo cual representa alrededor de la tercera parte de la población que debería de estar estudiando o terminando este nivel educativo. (INEGI, 2020). 
Gráfica 1. Porcentaje de la población de 15 años y más según nivel educativo.

Fuente: INEGI.
Ciertamente, existen múltiples factores para que una persona no tenga acceso a la educación superior, dentro de los cuales se encuentran los económicos, culturales, familiares, de salud, etc.

No obstante, si bien la educación elemental es obligatoria y es responsabilidad de los padres proveerla, cuando se es adulto mantenerse en situación de rezago educativo se ha convertido - en gran parte de los casos - en una elección, pues actualmente existen opciones para poder acceder a la educación básica, media superior y universitaria, tanto en el sector privado como en el público, de manera presencial como a distancia y semipresencial, sin importar la edad y con horarios flexibles y adecuados a las necesidades de cada persona, tales como las que ofrece el INEA, la SEP, la UNAM y el IPN, entre otras instituciones.

\section{Nivel de escolaridad en México}

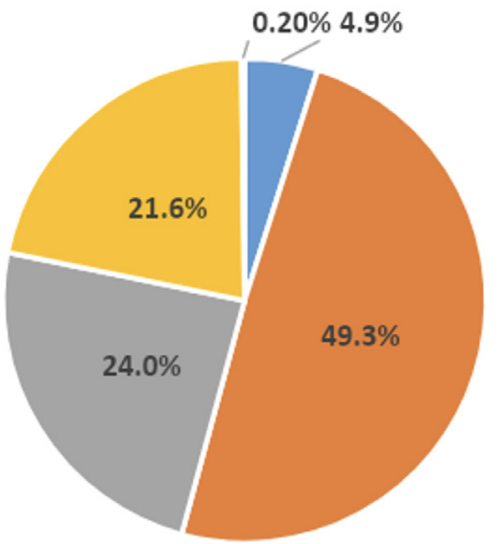

\author{
- Sin escolaridad \\ Básica \\ Media superior \\ Superior \\ No especificada
}

\section{El Sistema Universidad Abierta y Educación a Distancia (SUAyED)}

Por tal motivo, el Consejo Universitario de la unam bajo la filosofía humanista y el compromiso con la sociedad mexicana aprobó en 1972 la modalidad del Sistema Universidad Abierta que desde entonces ha representado una oportunidad de acceso a la educación universitaria que se ofrece de manera flexible para cubrir las necesidades educativas de los estudiantes sin que éstos tengan que descuidar otros aspectos de su vida, tales como la familia, la salud o el trabajo, entre otros.

Consiguientemente, durante este periodo la matrícula de educación superior aumentó de 327,100 entre 1972 y 1973 a 20,144,500 entre 1979 y 1980. (Rodríguez, R.1998).

Actualmente, el SUAYED atiende a cerca de 30,000 alumnos que representan $15 \%$ de la matrícula de la unAm. Asimismo, está conformado por un Consejo Asesor, por las facultades, escuelas, centros, institutos y sedes que ofrecen programas académicos, y por la Coordinación de Universidad Abierta, Innovación Educativa y Educación a Distancia (CUAIEED). 
Esta modalidad tiene una amplia oferta educativa de educación superior, posgrado y educación continua, con 22 licenciaturas en modalidad abierta, 20 licenciaturas en modalidad a distancia, 4 especializaciones en modalidad abierta, 2 especializaciones en modalidad a distancia, 3 programas de maestrías en la modalidad a distancia, 3 doctorados, 22 Entidades universitarias y Posgrados imparten programas en la modalidad abierta o a distancia, 8 sedes de Educación a Distancia en la República Mexicana en: Tlaxcala, Oaxaca, Chiapas, Hidalgo, Tabasco, Estado de México, Puebla, y Ciudad de México y Zona Metropolitana.

La modalidad de educación abierta del suAYED se lleva a cabo por medio de asesorías - principalmente grupales y programadas- con el docente dentro de la facultad o escuela. Mientras que en la modalidad a distancia estas asesorías ocurren de manera virtual, en grupo o individuales, por medio de videoconferencias y aulas virtuales. En ambas modalidades, el método de evaluación depende de cada escuela y facultad y cuentan con un periodo de evaluación ordinario y otro extraordinario.

Los alumnos pueden elegir el número de asignaturas a cursar por periodo semestral. Asimismo, cada estudiante es responsable de la organización de sus tiempos de estudio y debe de contar con habilidades digitales que le permitan realizar las actividades que le soliciten.

\section{Experiencia como estudiante del SUAyED}

Sin duda, como ex alumna del SUAYED, puedo afirmar que esta modalidad de estudio es una oportunidad de acceso a la educación universitaria para aquellos que por distintas razones no pudimos acceder a una licenciatura cuando estuvimos en edad de hacerlo o que por otras circunstancias no nos es posible estudiar dentro de la modalidad escolarizada, principalmente porque los horarios suelen ser más demandantes.

De manera personal, esta modalidad me permitió estudiar la Licenciatura en Pedagogía en la Facultad de Filosofía y Letras, de tal manera que pudiera seguir cumpliendo con mis labores de madre soltera, ama de casa y empleada.

Estudiar en la modalidad abierta de manera semipresencial también me dio la oportunidad de establecer lazos con mis compañeras y compañeros, maestras y maestros, y poder retroalimentar conocimientos y saberes dentro de las asesorías.

Es importante tener en cuenta que por tratarse de una modalidad distinta a la escolarizada no quiere decir que la calidad educativa, los aprendizajes adquiridos, los materiales de apoyo y el desempeño de los estudiantes y docentes sean menos valiosos.

Por el contrario, esta modalidad provee de habilidades metacognitivas autodidactas que permiten que los estudiantes lleven a cabo de manera individual y autónoma gran parte de los contenidos establecidos en el plan de estudios. 
La amplia gama de oferta educativa busca cubrir los intereses y necesidades de los aspirantes a esta modalidad que concursan por el ingreso en tres convocatorias a lo largo del año; sin embargo, hay carreras que no tienen la posibilidad de encontrarse dentro de esta modalidad, tales como las relacionadas al área de medicina.

En definitiva, confío en que la unAm a través del SUAYED amplíe dicha oferta educativa, así como el número de matrículas para que cada vez sean menos los que carezcan de educación universitaria y de posgrado.

Del mismo modo, creo que cada vez más personas tendrán la determinación de ampliar su nivel educativo a través de este sistema universitario que representa una gran oportunidad para quienes tenemos responsabilidades alternas, y con ello crear conciencia y cambiar el rol de objetos pasivos a sujetos activos en la construcción de una mejor sociedad.

Finalmente, agradezco infinitamente a la unAm por haber creado esta modalidad de estudio del SUAYED y brindar a través de ella una mejor calidad de vida para quienes tenemos la dicha de encontrar en este sistema la forma de materializar nuestros sueños universitarios.

"Por mi raza hablará el espiritu".

\section{Referencias}

* coneval. (2021, 5 de agosto) Nota técnica sobre el rezago educativo, 2018-2020. https://cutt.ly/KIpUCLS

* INEGI. (2020). Población. https://www.inegi.org.mx/temas/estructura/

* inegl. (2020). Características educativas de la población https://www.inegi.org.mx/ temas/educacion

* Rodríguez, R. (1998). "Expansión del sistema educativo superior en México 19701995", Tres décadas de políticas del Estado en la educación superior, México, ANuIEs, Pp. 167-205. https://cutt.ly/ZIplgcv

* unam. (2016).¿Qué es el Sistema Universidad Abierta y Educación a Distancia (SUAYED)? https://cutt.ly/alpOweL

* unam-dgcs. (2017, 2 de marzo). El Sistema Universidad Abierta y Educación A Distancia, clave en la proyección del futuro de la UNAM. https://cutt.ly/NIpOmwq

\section{Cómo CITAR ESTE ARTículo}

* Soberanes Gónzalez, Mariana. (2022, enero-febrero). El SUAyED y su papel ante la desigualdad educativa. Revista Digital Universitaria (RDU), 23(1). http://doi. org/10.22201/cuaieed.16076079e.2022.23.1.9 